\title{
BMJ Open Trends, composition and distribution of nurse workforce in China: a secondary analysis of national data from 2003 to 2018
}

\author{
Han Lu, ${ }^{1}$ Luoya Hou, ${ }^{1}$ Weijiao Zhou, ${ }^{2}$ Liqiong Shen, ${ }^{3}$ Shida Jin, ${ }^{1}$ Mengqi Wang, \\ Shaomei Shang (D) , ${ }^{1}$ Xiaomei Cong, ${ }^{4}$ Xiaoyan Jin, ${ }^{1}$ Dou Dou ${ }^{5}$
}

To cite: Lu H, Hou L, Zhou W, et al. Trends, composition and distribution of nurse workforce in China: a secondary analysis of national data from 2003 to 2018. BMJ Open 2021;11:e047348. doi:10.1136/ bmjopen-2020-047348

- Prepublication history and additional supplemental material for this paper are available online. To view these files, please visit the journal online (http://dx.doi.org/10.1136/ bmjopen-2020-047348).

$\mathrm{HL}$ and $\mathrm{LH}$ contributed equally. $\mathrm{SS}, \mathrm{XC}, \mathrm{XJ}$ and DD contributed equally.

Received 25 November 2020 Accepted 22 September 2021

D) Check for updates

(c) Author(s) (or their employer(s)) 2021. Re-use permitted under CC BY-NC. No commercial re-use. See rights and permissions. Published by BMJ.

For numbered affiliations see end of article.

Correspondence to Professor Shaomei Shang; shangshaomei@126.com, Dr Xiaomei Cong; xiaomei.cong@uconn.edu, Mrs Xiaoyan Jin; jxybmu@sina.com and Dr Dou Dou;

doudou@nsfc.gov.cn

\section{ABSTRACT}

Objectives Given the increased ageing population and frequent epidemic challenges, it is vital to have the nurse workforce of sufficient quantity and quality. This study aimed to demonstrate the trends, composition and distribution of nurse workforce in China.

Design Secondary analysis using national public datasets in China from 2003 to 2018.

Setting/participants National population, nurse workforce and physician workforce.

Primary and secondary outcome measures Frequency and proportion were used to demonstrate: (1) the longitudinal growth of nurse workforce; (2) the diversity of nurse workforce in gender, age, work experience and education level; and (3) the distribution of nurse workforce among provinces, rural-urban areas and hospital/ community settings. The Gini coefficient and Theil $L$ index were used to measure the inequality trends of nurse workforce.

Results The total number of nurses increased from 1.3 million to 4.1 million and the density increased from 1 to 2.94 per 1000 population over 2003-2018. The nurses to physician ratio changed from $0.65: 1$ to $1.14: 1$. The majority of the nurse workforce was female, under 35 years old, with less than 30 years of work experience, with an associate's degree and employed within hospitals. Central and eastern regions had more nurses and there were 5.08 nurses per 1000 population in urban areas while less than two in rural areas in 2018. The Gini coefficient and between-provincial Theil index experienced a consistent decline. Within-province inequality accounted for overall inequality has risen from $52.38 \%$ in 2010 to $71.43 \%$ in 2018 suggested that the differences of distribution are mainly reflected in urban and rural areas. Conclusion Chinese nurse workforce has been changed significantly in the past 15 years that may be associated with the reformations of policy, nursing education in China. Our study suggests current features in the nurse workforce and can be used to strengthen future health services.

\section{INTRODUCTION}

Nursing is the largest profession in the current healthcare workforce and healthcare service systems in China and worldwide. Nursing profession has been playing a central role in

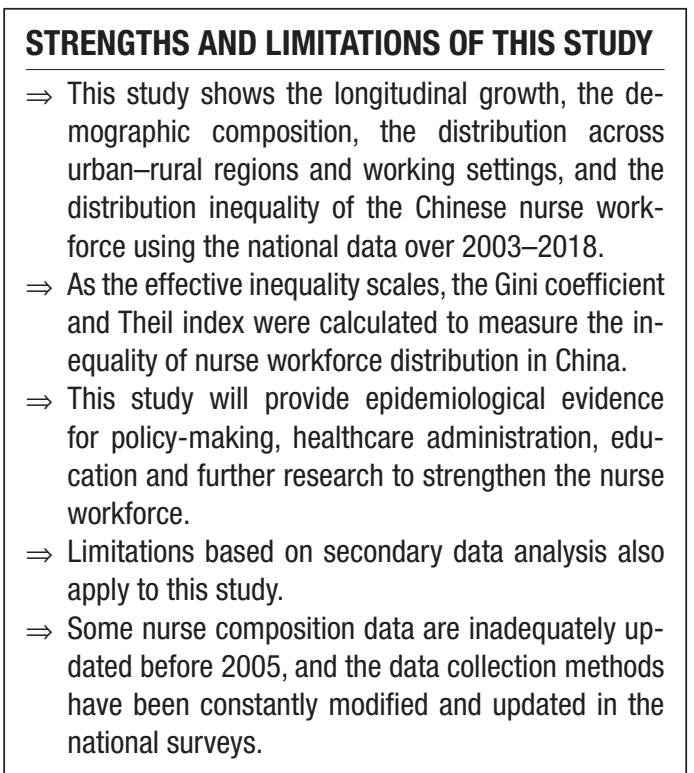

the health delivery system and providing a full range of responsibilities in health promotion, prevention, treatment and rehabilitation. There is a large variation of the growth of nursing workforce among different global regions and countries, and nursing shortage as well as other nursing workforce issues have always been a worldwide health service challenge. ${ }^{1}$ It is vital to have the nurse workforce of sufficient capacity, capability and quality in achieving population health and universal health coverage. A higher proportion of nurses, especially nurses with a higher education level in the health workforce is associated with better health outcomes. ${ }^{2-5}$ As the ageing population grows heavily globally, as well as the frequent public health emergencies in the past decades, there is an increasing need for safe and quality healthcare and nurse labour. ${ }^{6-8}$

WHO evidenced that despite significant progress, there is a growing mismatch 
between supply, need and demand of the nurse workforce, resulting in staff shortages. ${ }^{9}$ And WHO projected a significant growth $(55 \%)$ of nurse workforce demand, leading to an aggregate number of 32.3 million nurses/ midwives by 2030 based on current trends. ${ }^{10}$ Even in the USA, the nursing labour market continues to tighten with $45 \%$ of hospitals projecting to increase the number of nurse staff. ${ }^{11}$

As a middle-income country, China has been experiencing a very fast pace of the population ageing process and has the largest older population: more people are going to need more care for longer. In particular, the degree of ageing is showing an unbalanced trend. The proportion of people over 60 years old in rural areas $(20.6 \%)$ is higher than that in urban areas $(16.4 \%)$, while rural health resources have been largely underinvested and remain in deficit. ${ }^{12}$ These disparities lead to heavy healthcare burden in rural areas. Also, the inequality in the distribution of health resources between provinces cannot be ignored owing to the vast territory. ${ }^{13}$ As a result, China has been facing tremendous challenges regarding the nurse workforce. ${ }^{14}$

Over the past two decades, the systems of medical education and healthcare have undergone unprecedented reform in China. In essence, the educational composition is the reflection of economic structure on the demand for human resources. In 2001, China joined the World Trade Organization, boosting the development of finance. Under that circumstance, with the development of medical science and reform of the healthcare system, the composition of nursing education has made corresponding changes. In 2003, the Ministry of Education in China combined with the other five ministries defined nurses as a critically needed profession. ${ }^{15}$ To achieve a highly qualified nurse workforce, the government has taken this as a priority in healthcare management. During the 13th Five-Year plan (2016-2020) of China, the main goals of the nursing development have been established to prepare 4.45 million registered nurses or 3.14 nurses per thousand population by $2020 .^{16}$ As a result of that Five-Year strategic plan, there were almost 4.43 million nurses in China in 2019, which increased by nearly one million from $2016 .^{17}$

To date, the nurse workforce has improved significantly through the reform of healthcare system and health education in China. To our knowledge, the research is still lacking to demonstrate the trends of the Chinese nurse workforce from a national perspective. This study analysed the public data from the China Health and Family Planning Statistical Yearbooks (CHFPSY) and China Statistical Yearbooks (CSY), illustrating the current nurse workforce and trends of over 2003 to 2018 in China. Specifically, we examined: (1) the growth of the nurse workforce, (2) the compositions of nurse workforce, including the diversity in gender, age, work experience and education level and (3) the distribution of nurse workforce across provinces, rural-urban areas and healthcare settings.

\section{METHODS}

\section{Study design}

A secondary analysis design was used in the study. Data were retrieved from the CHFPSY and CSY. The two databases are national annual survey reports reflecting the statistics of the healthcare workforce, population health status, and economic and social aspects of 31 provinces, autonomous regions and municipalities in China (except for Hongkong, Macao and Taiwan areas). The annual data from 2003 to 2018 from the CHFPSY (yearbooks of 2004-2019) were used in analysing the trends, composition and distribution of the nurse workforce over the past 15 years. We also used the CSY dataset to retrieve the population data of the national and province levels and calculated the equality/inequality of the distribution of nursing resources over 2003-2018 in China.

\section{Variables and definitions}

The primary variables and definitions included in the data analysis are described as the following, which are corresponding to the national survey datasets:

1. Nurses are those who have passed the nurse qualification examination and obtained a nursing qualification.

2. Physicians are those who pass a licensing examination and are registered at a healthy authority, including licensed physicians and licensed physician assistants.

3. Hospitals include general hospitals, affiliated hospitals of medical college, hospitals specialised in traditional Chinese medicine, hospitals of integrated traditional Chinese with western medicine, national hospitals, specialised hospitals and nursing homes.

4. Primary care institutions include community health service centres, community health service stations, urban health centres, township health centres, village clinics and outpatient departments and health centres.

5 . The urban areas include municipalities and prefecturelevel municipalities.

6 . The rural areas include counties and county-level cities, townships and villages.

7. The density of nurses is defined as the number of nurses per 1000 population.

\section{Data analysis}

We downloaded the data from each of the yearbook datasets from 2004 to 2019, which correspond to the nurse and population data of 2003-2018. Excel software was used to merge, manage and analyse the data. We used frequency and proportion to describe the composition and distributions of the nurse workforce throughout 2003-2018. The growth rate of nurses was calculated as the annual increased number of nurses divided by the total number of nurses of the previous year.

As for the inequality of nursing distribution, we adopted the Gini coefficient and Theil L index, which have been proposed by the WHO to describe the inequality of the health workforce and applied in measuring the health workforce in China and India. ${ }^{18}$ The Gini coefficient, an indicator for judging the degree of equality of distribution 
according to the Lorenz curve, though not decomposable, is the most well-known indicator to measure the aggregate level of inequality. We sorted the number of nurses per 1000 population in each province from small to large, using the cumulative population percentage as the abscissa and using the cumulative percentage of nurses as the ordinate to draw the Lorenz curve of the distribution of nurses across the country by population. The Gini coefficient is twice the area enclosed by the Lorenz curve and the perfect equality line. ${ }^{19}$ If $b_{i}=$ number of nurses in province unit $i$ and $\mathrm{c}_{i}=$ number of people in province unit $i$, then the total number of nurses in the country is $\mathbf{B}=b_{1}+b_{2}+\ldots+b_{n}$ and the total number of people in the country is $C=c_{1}+c_{2}+\ldots+c_{n}$. If we value $\mathrm{B}_{\mathrm{i}}=\mathrm{b}_{\mathrm{i}} / \mathrm{B}, \mathrm{C}_{\mathrm{i}}=\mathrm{c}_{\mathrm{i}} / \mathrm{C}$, then the Gini coefficient $G=1-\sum_{i=1}^{I} C_{i}\left(2 \sum_{i=1}^{I} B_{i}-B_{i}\right)$. For further analysis, the Theil $\mathrm{L}$ index is the most attractive decomposition indicator, as it can be decomposed into two parts, between-groups $\left(T_{1 L}\right)$ and within-groups $\left(T_{2 L}\right)$, respectively. If $j$ means urban or rural, then $\mathrm{B}_{\mathrm{ij}}$ means the proportion of urban or rural nurses in province unit $i$ in the total nurses, and $\mathrm{C}_{\mathrm{ij}}$ means the proportion of the urban or rural population in province unit $i$ in the total population. The decomposition of Thiel $\mathrm{L}$ index is as follows:

$$
\text { Theil } \mathrm{L}=\mathrm{T}_{1 \mathrm{~L}}+\mathrm{T}_{2 \mathrm{~L}}=\sum_{\mathrm{i}=1}^{\mathrm{I}} \mathrm{C}_{\mathrm{i}} \log \frac{\mathrm{C}_{\mathrm{i}}}{\mathrm{B}_{\mathrm{i}}}+\sum_{\mathrm{i}=1}^{\mathrm{I}} \mathrm{C}_{\mathrm{i}} \sum_{\mathrm{j}=1}^{\mathrm{J}} \mathrm{C}_{\mathrm{ij}} \log \frac{\mathrm{C}_{\mathrm{ij}}}{\mathrm{B}_{\mathrm{ij}}}
$$

This study calculated the Gini coefficient and Theil L index to estimate the level of equality among nurse distribution and they were all weighted by the proportion of the population in each province in the total population as we explained in the formula. Besides, we calculated the ratio of the provincial Theil index to the total Theil index to represent the contribution rate of urban-rural differences to total differences. ${ }^{20}$ The Gini coefficient and Theil $\mathrm{L}$ value from 0 to 1 . The smaller value means fairer nurse distribution. We use Microsoft Excel 2013 to perform the above analyses.

\section{Patient and public involvement}

A few nurses were involved in the reporting of our research and gave suggestions on the content and presentation of our research.

\section{RESULTS}

\section{Growth of nurse workforce}

Over 15 years, the nurse workforce has grown dramatically in China. At the end of 2018, the number of nurses reached over four million, which is 2.2 times more than that in 2003. The density of nurses increased by 1.9 times in the same period to reach about 2.94 nurses per 1000 population in 2018 (table 1 and figure 1). In figure 2, the growth rates of the nurse workforce reveal three segments: an initial period of growth (2003-2006), a rapid growth period (2007-2013) and a period of stable growth (2014-2018). In the initial growth period, the
Table 1 Change of nurse and physician workforce from 2003 to 2018

\begin{tabular}{lllllll}
\hline & \multicolumn{2}{c}{ Nurses } & & \multicolumn{2}{c}{ Physicians } \\
\cline { 2 - 3 } \cline { 5 - 6 } Year & No & Density* & No & Density* \\
\hline 2003 & 1265959 & 1.00 & 1942364 & 1.54 \\
\hline 2004 & 1308433 & 1.03 & 1999457 & 1.57 \\
\hline 2005 & 1349589 & 1.03 & 2042135 & 1.56 \\
\hline 2006 & 1426339 & 1.09 & & 2099064 & 1.60 \\
\hline 2007 & 1558822 & 1.18 & & 2122925 & 1.61 \\
\hline 2008 & 1678091 & 1.2 & 2201904 & 1.66 \\
\hline 2009 & 1854818 & 1.39 & 2329206 & 1.75 \\
\hline 2010 & 2048071 & 1.53 & & 2413259 & 1.80 \\
\hline 2011 & 2244020 & 1.66 & 2466094 & 1.82 \\
\hline 2012 & 2496599 & 1.85 & 2616064 & 1.94 \\
\hline 2013 & 2783121 & 2.04 & 2794754 & 2.04 \\
\hline 2014 & 3004144 & 2.20 & & 2892518 & 2.12 \\
\hline 2015 & 3241469 & 2.37 & 3039135 & 2.22 \\
\hline 2016 & 3507166 & 2.54 & 3191005 & 2.31 \\
\hline 2017 & 3804021 & 2.74 & 3390034 & 2.44 \\
\hline 2018 & 4098630 & 2.94 & 3607156 & 2.59 \\
\hline
\end{tabular}

*Per 1000 population.

growth rate dramatically increased from $1.6 \%$ in 2003 to $5.7 \%$ in 2006. The rapid growth period began in 2007 (9.3\%), declined slightly in 2008 and 2011, then rose and reached the highest growth rate $(11.5 \%)$ in 2013. Since 2014 , there was a stable growth rate ranged from $7.7 \%$ to $8.5 \%$.

Meanwhile, we also compared nurses vs physician workforce in China (table 1). In a long period of history before 2014, China had been with more physicians than nurses (figure 1). With the rapid expansion of the nursing staff, the imbalance of nurses and physicians has been changed, and the ratio of nurses to physicians changed from 0.65:1 in 2003 to $1.14: 1$ in 2018 .

\section{Nurse demographics and characteristics}

Table 2 presents nurse demographics and characteristics in overall health institutions, hospitals and primary care institutions in China between 2005 and 2018 (no data available before 2005). The nurse workforce in China has been always predominately female, with the proportion of male nurses slightly increased from $1.7 \%$ in 2005 to $2.3 \%$ in 2018. Figure 3 shows the different composition of male nurses in hospitals versus primary care institutions. From 2005 to 2018, male nurses working in primary care institutions dropped to $1.3 \%$, while the proportion in hospitals steadily rose from $1.6 \%$ to $2.7 \%$.

Young nurses are the main force of the nurse workforce in China. Employees under 35 years were accounted for $60.3 \%$ of the total nurses in 2018. In table 2, the proportion of nurses between the age of 25 and 34 and those over 55 years increased during 2005-2018, whereas 


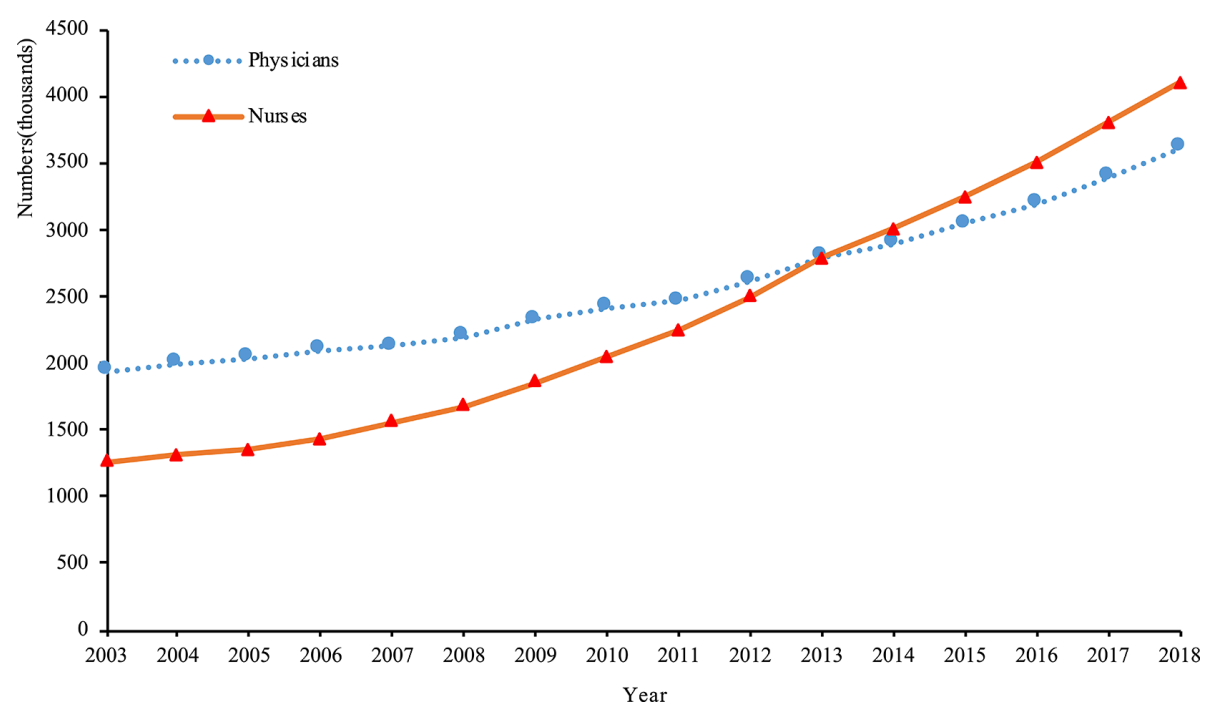

the proportion of nurses between 35 and 54 declined slightly. Moreover, the proportion of nurses between 25 and 34 years old grew gradually in hospital settings but decreased in the primary care institutions across the 15 years. In 2018, there were more young nurses (under 35 ) in hospitals than primary care institutions.

The nurses' educational levels have changed over time with an increased proportion of the higher level of degrees. The percentage of nurses with a vocational education degree or below dropped year by year, from $74.4 \%$ in 2002 to $30.2 \%$ in 2018. Associate's degree nurses have become the main force of registered nurses in China, accounting for $48.9 \%$ in 2018. The growth of nurses with bachelor's, master's or Ph.D. degree was fast over the period. By the end of 2018, the proportion of nurses with a bachelor's degree or above have reached $21.0 \%$. Compared with primary care settings, hospitals had more nurses with higher education levels.

The proportion of experienced nurses who were serving more than 30 years was relatively small in China nurse workforce. The proportion of nurses with 10-29 years' work experience has decreased continually ( $58.6 \%$ in 2005 to $38.2 \%$ in 2018 ), while the percentage of nurses with less than 10 years' experience increased ( $33.5 \%$ in 2005 to $52.5 \%$ in 2018 ). A similar trend was shown overtimes for the distribution of nurse working experience in the hospital and primary care settings, but more hospital nurses had less than 10 years' work experience, and more primary care nurses were with more than 20 years' work experience.

\section{Distribution across provinces, rural-urban areas and settings}

We adopted the latest data of 2018 to analyse the nurse distribution among different provinces in China. The density of nurses in each of the provinces and areas ranged from approximately a high of 5.0 nurses in Beijing to a low of 1.6 nurses per 1000 population in Tibet. Figure 4 shows that the provinces in the northeastern and western regions had a relatively low density of the nurse workforce, whereas provinces in the central

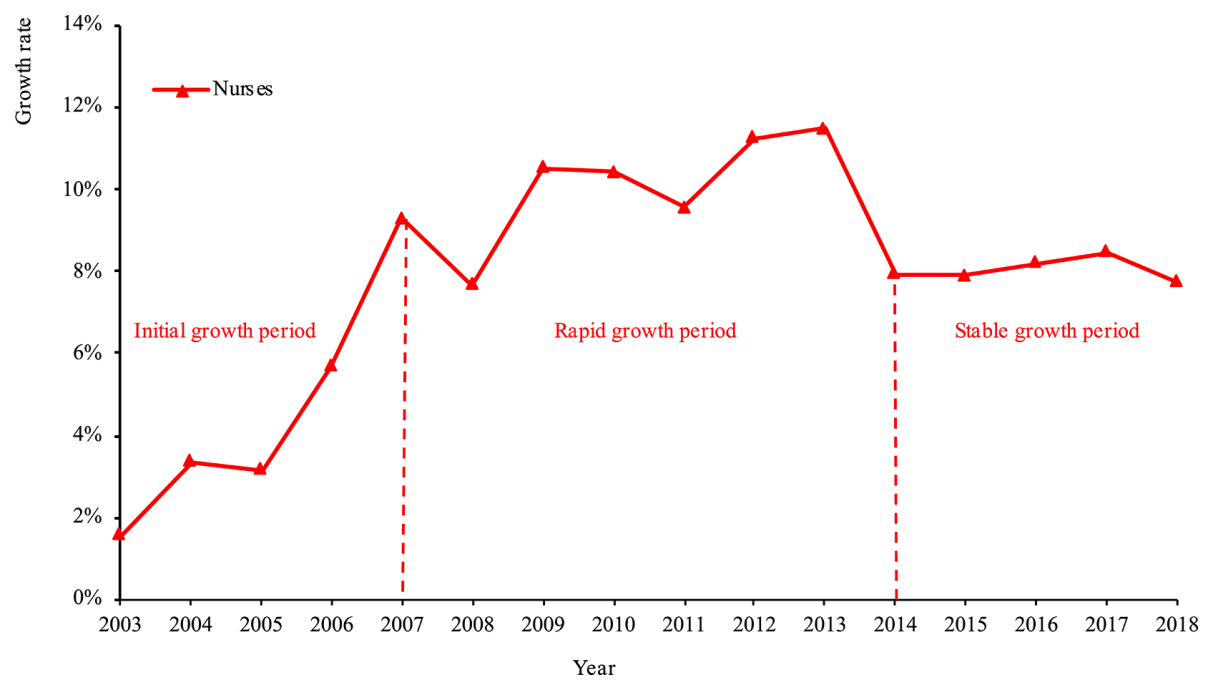

Figure 2 The growth rates in the supply of nurses from 2003 to 2018. 
Table 2 Demographics and characteristics of nurses from 2005 to 2018

\begin{tabular}{|c|c|c|c|c|c|c|c|c|c|c|c|c|}
\hline \multirow[b]{2}{*}{ Year } & \multicolumn{4}{|c|}{ Overall health institutions } & \multicolumn{4}{|c|}{ Hospitals } & \multicolumn{4}{|c|}{ Primary care institutions* } \\
\hline & 2005 & 2010 & 2015 & 2018 & 2005 & 2010 & 2015 & 2018 & 2005 & 2010 & 2015 & 2018 \\
\hline \multicolumn{13}{|l|}{ Gender } \\
\hline Female & 98.3 & 98.3 & 98.0 & 97.7 & 98.4 & 98.2 & 97.8 & 97.3 & 97.7 & 98.5 & 98.7 & 98.7 \\
\hline \multicolumn{13}{|l|}{ Age } \\
\hline $25-34$ & 40.3 & 39.6 & 46.8 & 50.6 & 38.2 & 39.0 & 48.8 & 53.1 & 52.6 & 42.5 & 39.9 & 42.7 \\
\hline $35-44$ & 31.6 & 26.9 & 22.0 & 22.1 & 32.7 & 26.6 & 19.9 & 20.6 & 25.6 & 30.1 & 31.6 & 28.7 \\
\hline $45-54$ & 17.3 & 16.9 & 14.0 & 12.7 & 18.1 & 17.6 & 13.7 & 12.1 & 12.1 & 13.4 & 14.7 & 16.3 \\
\hline $55-59$ & 0.6 & 2.2 & 2.0 & 3.4 & 0.6 & 2.0 & 1.9 & 3.4 & 0.5 & 1.5 & 1.4 & 2.7 \\
\hline 60 or above & 0.1 & 0.4 & 1.1 & 1.5 & 0.1 & 0.2 & 0.7 & 1.1 & 0.1 & 0.2 & 0.4 & 0.6 \\
\hline $5-9$ & 19.4 & 16.2 & 24.1 & 31.2 & 17.5 & 16.5 & 24.8 & 32.5 & 30.2 & 13.8 & 21.0 & 27.2 \\
\hline $10-19$ & 35.9 & 29.1 & 20.6 & 23.9 & 36.3 & 27.2 & 19.1 & 23.7 & 35.0 & 39.0 & 25.8 & 23.6 \\
\hline 20-29 & 22.7 & 21.8 & 16.7 & 14.3 & 23.8 & 22.8 & 16.1 & 13.1 & 16.6 & 18.9 & 20.5 & 21.4 \\
\hline 30 or above & 7.7 & 9.3 & 8.8 & 9.3 & 8.3 & 9.3 & 8.5 & 9.1 & 3.9 & 7.2 & 6.9 & 8.3 \\
\hline \multicolumn{13}{|l|}{ Education } \\
\hline Master's or above & 0.0 & 0.1 & 0.1 & 0.2 & 0.0 & 0.1 & 0.2 & 0.2 & 0.0 & 0.0 & 0.0 & 0.0 \\
\hline Bachelor's & 2.7 & 8.7 & 14.5 & 20.8 & 3.2 & 10.5 & 16.7 & 23.5 & 0.4 & 2.6 & 6.9 & 13.4 \\
\hline Associate's & 28.9 & 42.5 & 47.9 & 48.9 & 31.8 & 45.5 & 50.3 & 50.4 & 14.1 & 32.8 & 39.9 & 44.4 \\
\hline Vocational education & 60.4 & 46.0 & 36.3 & 29.6 & 57.7 & 41.5 & 31.9 & 25.5 & 73.9 & 60.4 & 51.2 & 41.1 \\
\hline
\end{tabular}

*Estimated by authors based on demographics data of community health service stations and township health centres.

and eastern regions tended to have a high nurse per capital supply.

As for the urban-rural distribution of nurses in China, the criteria used in the datasets for dividing urban and rural areas before 2010 were different from those for the recent years, therefore, we used the data from 2010 to 2018 for analysis. The data show that there were large differences between urban and rural areas. In 2010, there were more than 3 nurses per 1000 population in urban areas, while there was less than 1 nurse per 1000 population among rural areas. Over the past decade, the number and density of nurses in both urban and

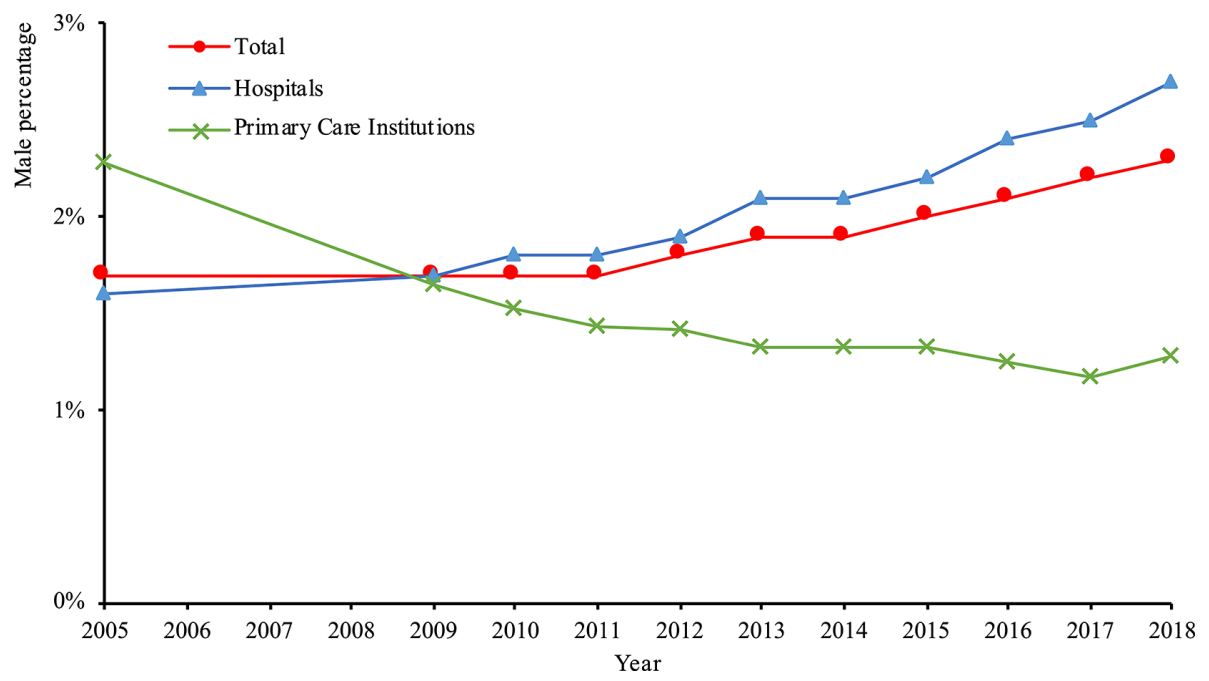

Figure 3 Change of the proportion of male nurses from 2005 to 2018. 


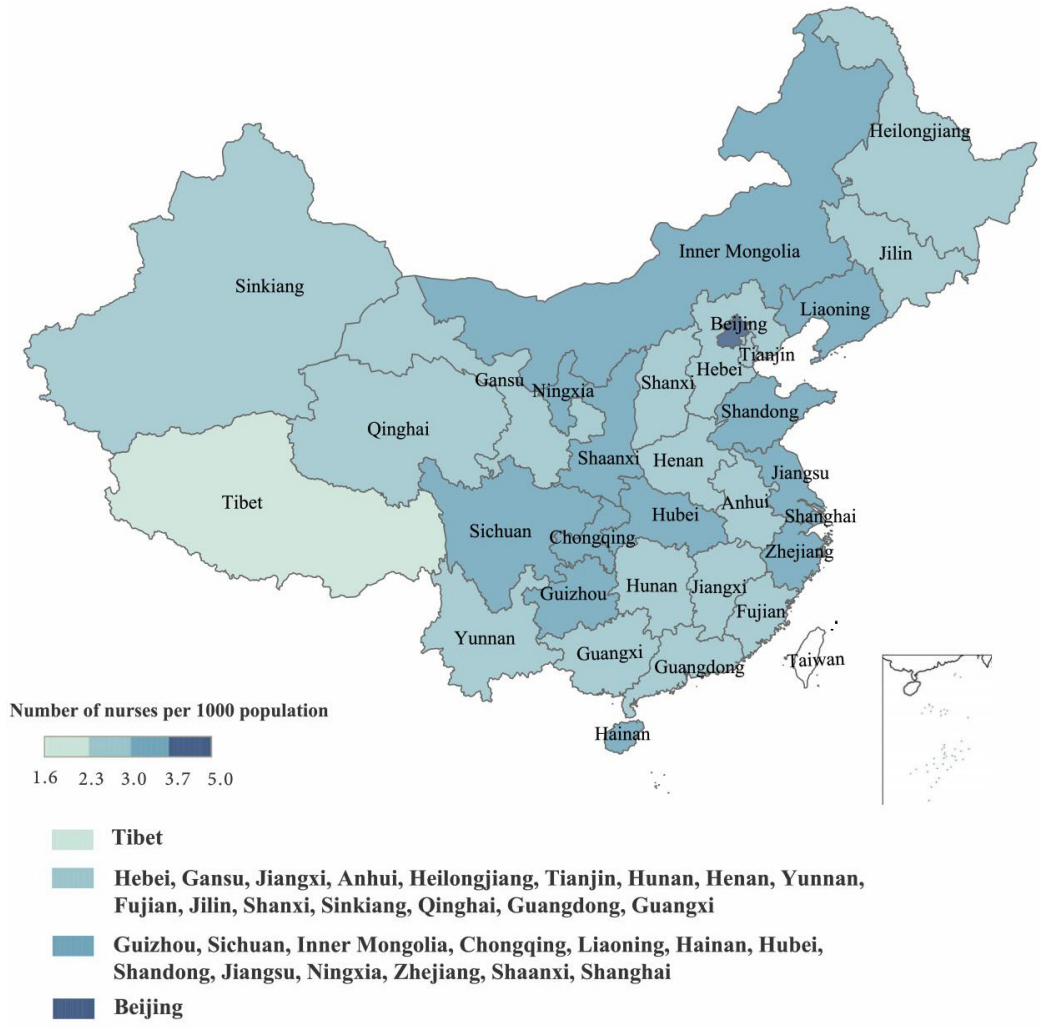

Figure 4 Distribution of nurses across provinces in China, 2018.

rural areas have greatly increased, but the gap between urban and rural areas has not been narrowed. By 2018, there were 5.08 nurses per 1000 population in urban areas, while the number of that in rural areas was still less than 2 (online supplemental file).

In 2018, the majority of nurses $(73.70 \%)$ were employed within hospital settings, and only about $20 \%$ of nurses worked in primary care institutions (see figure 5). Over the past 10 years, there was a tendency that more patients went to hospitals rather than primary care institutions (online supplemental file). Hospitals received more than $70 \%$ of inpatients and $40 \%$ of overall outpatient visits, and primary healthcare institutions were responsible for over $50 \%$ of the visits and $20 \%$ of inpatients. During the last decade, although the number of nurses working in all institutions has

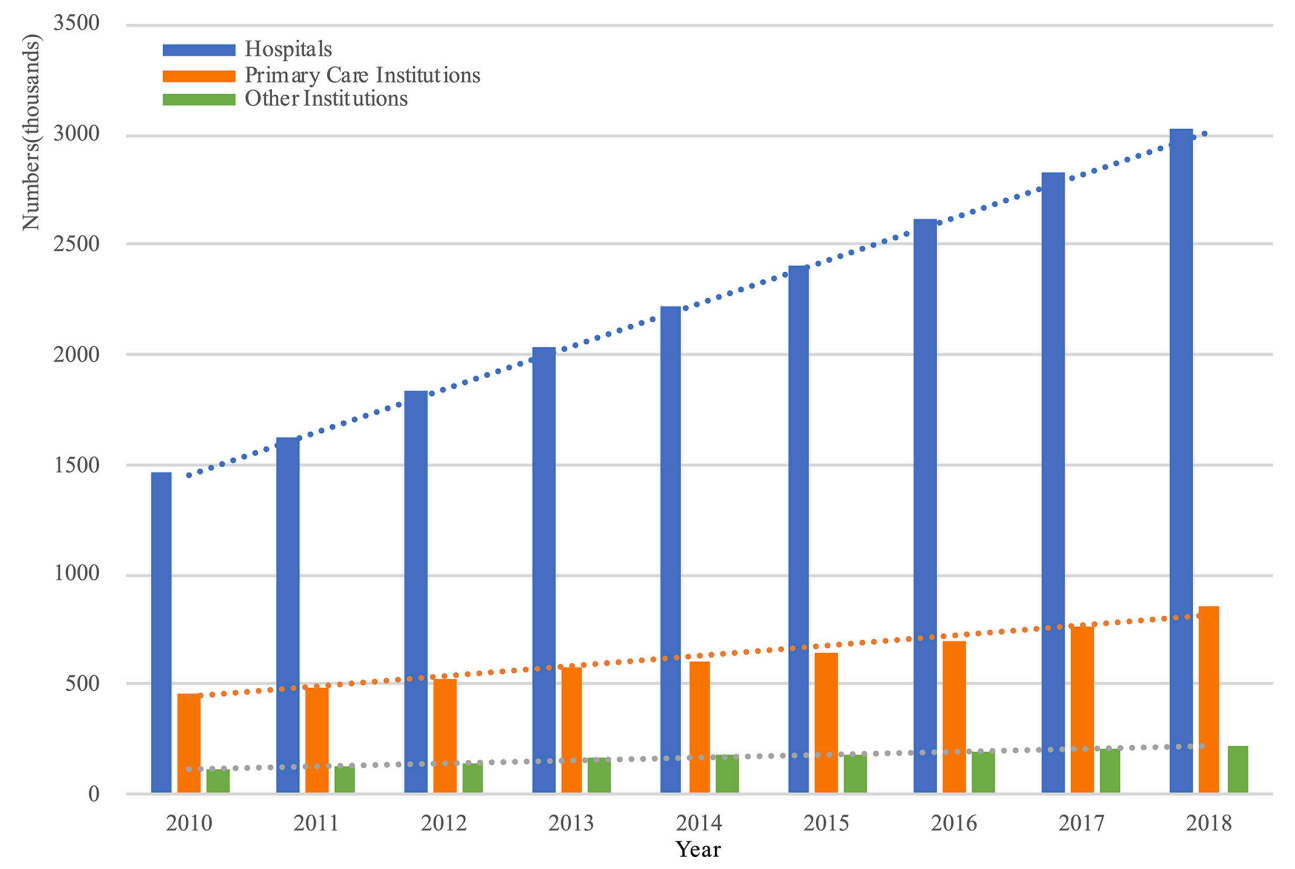

Figure 5 Change of nurse distribution across settings in China from 2010 to 2018. 
increased significantly, the distribution of nurses across settings had no significant changes.

To further examine the distribution of equality of the nurse workforce, we calculated the Gini coefficient and Theil L index. Although the analyses were based on the provincial data, due to the lack of valid individual residential data, the results demonstrated significance for understanding the distribution across provinces and between the urban and rural areas over the country. The Gini coefficient of nurses fell from 0.167 in 2010 to 0.119 in 2018. Between-provincial Theil index had similar trends to the corresponding Gini index, dropped from 0.010 in 2010 to 0.004 in 2018. Overall and within-provincial Theil index experienced a decline from 2010 to 2015 and has risen again in the past 3 years. Within-province inequality accounted for overall interprovincial inequality has risen consistently, with a peak in 2018 (Theil L: from $52.38 \%$ in 2010 to $71.43 \%$ in 2018) (online supplemental file).

\section{DISCUSSION}

Understanding the nurse workforce trends, composition and distribution of supply is crucial for building an effective healthcare system. The current study presents national data with longitudinal and recent status on the nurse workforce in China from 2003 to 2018. To the best of our knowledge, this is the first study to report trends of the nurse workforce on a large scale, national level and over the past 15 years of period. As in many ways, the nursing human resources and education, and health and family policy all impact each other, ${ }^{21}$ the results of the analysis in this article can be used for policy-making, healthcare administration, education and further research to strengthen nurse workforce.

The number of Chinese nurse workforce in 2017 (3.8 million) accounted for $18 \%$ of the nurse workforce in the world (20.7 million), and this number increased to 4.1 million in 2018. ${ }^{22}$ The Chinese nurses per 1000 population were 2.94 in 2018, exceeding the minimum standard set by WHO (2 nurses per 1000 populations) and some developing countries (eg, India and South Africa), yet this density is still relatively below the average density of Organisation for Economic Co-operation and Development member countries (9 nurses per 1000 populations and $50 \%$ of WHO Member States in 2017). ${ }^{22}{ }^{23}$ The ratio of nurses to physicians is another widely used indicator to show nurse supply. The trends in the number of physicians and nurses in figure 1 indicate intuitive changes in the ratio of nurses to physicians in the past 15 years. The size of physicians over nurses had been consistently large in China until the changes occurred in 2014, for the first time, the problem of an inverted ratio of doctors to nurses was reversed. The larger size of physicians over nurses during a long period of history in China is associated with many factors and one of the reasons may be related to the duties and responsibilities of nurses and physicians different from other countries. ${ }^{24}$ Physicians in
China have been responsible for some patient care, which may be taken charge of by nurses in other countries.

Besides, we found that changes in growth rates of the nurse workforce were highly associated with policy shifts. In 2003, The Chinese Ministry of Education and the Ministry of Health issued the policies highlighting the nursing shortage, encouraging higher nursing education and addressing the development of community health services, ${ }^{15}$ as such, our data show a milestone for the growth of nurse workforce at that period. In 2008, the healthcare system reform began in China, aimed to strengthen the nurse workforce, which was another significant impact on nursing growth. ${ }^{25}$ In 2011, the Ministry of Education of the People's Republic of China issued a document to set nursing as a first-level discipline independent of clinical medicine admissions. ${ }^{26}$ The number of nursing colleges and nursing programmes has increased steadily, ensuring a rapid increase in the number of nurses. ${ }^{27}$ Although the initial implementation of healthcare reform policy and the global financial crisis may affect the growth rate slightly in 2008, nurses' numbers were in a period of rapid growth, which brings about the number of nurses surpassed the number of physicians for the first time in 2014. In recent years, the support of national policies, and the increase in specialist nurses' training programmes and bases increased the social recognition and attractiveness of nursing positions. Accordingly, a certain number of outstanding talents for Chinese nursing were attracted. However, the ratio of nurses to physicians is still not adequately balanced compared with many developed and low/middle-income countries worldwide. ${ }^{1}$ Given that, along with an increasingly severe ageing population and frequent epidemic challenges, it is vital to adopt effective policies attracting more talents to enter nursing practice.

Growing and developing a more diverse and sustainable nursing workforce in China is still challenging in achieving the goal of health equity. Female nurses dominate and males $(2.3 \%)$ remain largely underrepresented in the nursing profession in China, in comparison with the proportion of male nurses in the USA $(9.6 \%)$ and the UK (10.7\%), which may be related to different cultures and efforts to increase the gender diversity in nursing. ${ }^{28} 29$ Meanwhile, our finding shows that along with the increased proportion of male nurses, the nurse workforce in China is slowly becoming more diverse over time. There is a high demand for male nurses in China, especially after China implemented the universal twochild policy in 2016. Moreover, male nurses show great advantages in physical strength, mental toughness and mechanics sensitivity. Accordingly, Chinese male nurses have better career prospects and promotion chances compared with female nurses. ${ }^{30}$ The occupational cognition of male nurses is also improving in China in recent years. ${ }^{31}$ Notably, China's nurse workforce has been also dominated by young and middle-aged nurses, with more than $70 \%$ of nurses being 22-44 years but the proportion of nurses with more than 30 years of experience consistently below $10 \%$. This unbalanced composition of age 
and working experience may result from the continuous nurse shortage in the past 30 years and rapid expansion in the past decades, for instance, in 1990, China had 1.14 billion people but only fewer than one million nurses. The severe shortage of nurses in the past has led to a shortage of senior and clinically experienced nurses today, significantly, the proportion of nurses over 55 years old in China $(4.9 \%)$ is small, compared with the USA (46\%) and the UK (19\%). ${ }^{28}{ }^{29}$ This is mainly due to China's retirement policy, where most women retire at the age of 55. In another respect, the young nurse workforce is an invaluable asset of the healthcare system in China in addressing the shortage of nursing and dealing with social health issues. In the period of fighting the COVID-19 epidemic in Wuhan, nurses aged 40 or under accounted for more than $90 \%$, playing a vital role in fighting the virus. When the policy-makers are seeking solutions to overcome the nurse shortage, it is crucial to consider and develop strategies to retain the nurses in the workforce and extend their career. Nursing workforce development and retention strategies need to promote different gender and age and experience groups of nurses. For instance, research has shown that young nurses are more likely to leave due to the imbalance between effort and reward, high psychological demands and elevated job strain, which suggests that policy-makers need to provide young nurses with sufficient social support and the balance between effort and rewards such as salary, recognition and career opportunities to attract and retain young nurses. ${ }^{32} 33$

As for the educational level of nurses, our results confirmed that it was not until 2010 the educational composition of nurses shifted from the main body of vocational education and blow to associate's degree and above. Although there is a gradual increase in the proportion of nurses with an associate degree and bachelor's degree or above, there is still a gap between China and developed countries. ${ }^{28} 29$ There was only $2.7 \%$ of nurses who have received a bachelor's degree in 2005. The main reason for the low percentage was that undergraduate nursing education had not restarted until 1983 with over twenty years of break in China. ${ }^{34}$ However, as of 2006, a total of 192 colleges and universities across the country enrolled nursing undergraduates, with more than 20000 students enrolled. ${ }^{34}$ By 2018, there were over 260 colleges and universities that cultivated nursing undergraduates, while $21 \%$ of nurses obtained a bachelor's degree and above. The evidence that nurses with higher education contribute greatly to producing high-quality care is strong. Studies report a significant association between educational level and patient outcomes, including mortality rates. ${ }^{45}{ }^{36} \mathrm{It}$ is urgent to improve the education level of nurses in China. At the policy level, while encouraging the development of advanced nursing education, it is necessary to consider providing a broader career development path for highly educated nurses, so as to attract nurses to pursue high education and retain highly educated nursing talents. In addition, considering that many nurses in China have only received an associate's and vocational education, continuing education needs to be vigorously developed. Potential strategies include providing financial advising, academic advising, and open access to programmes (eg, flexible schedules and/ or online courses) ${ }^{3738}$ Also, a higher education expectation and supportive approaches from the employer may motivate nurses to continue their education. ${ }^{37} 39$

The nurse workforce is lack of diversity and unequally distributed across China. The results demonstrated a substantial variation of nursing resources across geographical and/or economic areas: a high concentration of nurses/providers within urban and/or affluent areas, versus a relative undersupply in rural and/or lowincome areas. Such imbalance in the nurse workforce is neither unique to China nor to global nurse providers, which is a worldwide problem for all healthcare professionals. ${ }^{40}$ By calculating the Gini coefficient and Theil $\mathrm{L}$ index, we found that the differences in the distribution of nurses in China are mainly reflected in urban and rural areas, while distribution inequality across provinces was decreasing in recent years. Considering that there are more elderly and children in need of healthcare reside in rural areas of China, it suggests that in the future, more attention should be paid to the urban-rural gap when focusing on health equity between provinces. In terms of distribution in different settings, the majority of nurses are still employed within the hospitals, despite policies that have aimed to strengthen primary care and shift health services towards the community. ${ }^{15} 42$ The proportion of nurses employed in hospitals in China is higher compared with developed countries (eg, England, Japan and the USA). To address the imbalanced distribution of healthcare professionals, evidence-based interventions/ strategies are suggested, including focused recruitment and training, improved living and working environment, and financial and professional incentives. ${ }^{434}$

\section{Limitations}

This study is the first to report trends, composition and distribution of the Chinese nurse workforce over 20032018. However, there are some limitations to the study. First, there is no nurse composition data available before 2005 from CHFPSY/CSY, and we have not found any related data or survey. Despite some data gaps, we used the largest available data which was meant to reflect the latest trends. Second, as the data collection methods have been constantly modified and updated in the national surveys, it would have a certain impact on our analysis. A new criterion of urban and rural classification was adopted in 2010, which brought the incomparability of urban-rural distribution over time. In this case, we conduct analysis using data that adopt the latest standards to enhance the comparability of the results across times.

\section{CONCLUSION}

Significant changes in China's nurse workforce have been found over time, such as a great increase in the 
total number of nurses, improvement in education and decreasing nurse workforce inequality. These changes might be highly associated with policy reformations and social and economic needs at the national and global levels. Our study also suggests current features in the nurse workforce. Nurses in China are featured with less gender diversity, tend to be younger and have lower education level compared with developed countries. Findings in our study provide evidence to inform nurse workforce policy, education and healthcare services in the future.

\section{Author affiliations}

${ }^{1}$ Peking University School of Nursing, Beijing, China

${ }^{2}$ University of Michigan School of Nursing, Ann Arbor, Michigan, USA

${ }^{3}$ Wuhan University Zhongnan Hospital, Wuhan, Hubei, China

${ }^{4}$ Nursing Biobehavioral Research Laboratory (BBL), University of Connecticut School of Nursing, Storrs, Connecticut, USA

${ }^{5}$ Forth Department of Health Sciences, National Natural Science Foundation of China, Beijing, China

Contributors $\mathrm{HL}$ and $\mathrm{LH}$ are joint first authors. SS, $\mathrm{XC}, \mathrm{XJ}$ and $\mathrm{DD}$ designed the study. HL, SJ and MW collected the data. LH, HL and WZ analysed the data. HL and LH drafted the manuscript. LS and WZ revised the manuscript. All authors have read and approved the final manuscript. SS, XC and DD are the study guarantors.

Funding The authors have not declared a specific grant for this research from any funding agency in the public, commercial or not-for-profit sectors.

Map disclaimer The inclusion of any map (including the depiction of any boundaries therein), or of any geographic or locational reference, does not imply the expression of any opinion whatsoever on the part of BMJ concerning the legal status of any country, territory, jurisdiction or area or of its authorities. Any such expression remains solely that of the relevant source and is not endorsed by BMJ. Maps are provided without any warranty of any kind, either express or implied.

Competing interests None declared.

Patient consent for publication Not applicable.

Provenance and peer review Not commissioned; externally peer reviewed.

Data availability statement Data are available in a public, open access repository. The access policy and procedures are available at https://data.cnki.net/yearbook.

Supplemental material This content has been supplied by the author(s). It has not been vetted by BMJ Publishing Group Limited (BMJ) and may not have been peer-reviewed. Any opinions or recommendations discussed are solely those of the author(s) and are not endorsed by BMJ. BMJ disclaims all liability and responsibility arising from any reliance placed on the content. Where the content includes any translated material, BMJ does not warrant the accuracy and reliability of the translations (including but not limited to local regulations, clinical guidelines, terminology, drug names and drug dosages), and is not responsible for any error and/or omissions arising from translation and adaptation or otherwise.

Open access This is an open access article distributed in accordance with the Creative Commons Attribution Non Commercial (CC BY-NC 4.0) license, which permits others to distribute, remix, adapt, build upon this work non-commercially, and license their derivative works on different terms, provided the original work is properly cited, appropriate credit is given, any changes made indicated, and the use is non-commercial. See: http://creativecommons.org/licenses/by-nc/4.0/.

\section{ORCID iD}

Shaomei Shang http://orcid.org/0000-0002-3913-4570

\section{REFERENCES}

1 Drennan VM, Ross F. Global nurse shortages-the facts, the impact and action for change. Br Med Bull 2019;130:25-37.

2 Haegdorens F, Van Bogaert P, De Meester K, et al. The impact of nurse staffing levels and nurse's education on patient mortality in medical and surgical wards: an observational multicentre study. BMC Health Serv Res 2019;19:864.
3 Amiri A, Vehviläinen-Julkunen K, Solankallio-Vahteri T, et al. Impact of nurse staffing on reducing infant, neonatal and perinatal mortality rates: evidence from panel data analysis in 35 OECD countries. Int $J$ Nurs Sci 2020;7:161-9.

4 Aiken LH, Sloane DM, Bruyneel L, et al. Nurse staffing and education and hospital mortality in nine European countries: a retrospective observational study. Lancet 2014;383:1824-30.

5 Amiri A, Solankallio-Vahteri T, Arshia A. Nurse-staffing level and quality of acute care services: evidence from cross-national panel data analysis in OECD countries. Int J Nurs Sci 2019;6:6-16.

6 James SL, Abate D, Abate KH, et al. Global, regional, and national incidence, prevalence, and years lived with disability for 354 diseases and injuries for 195 countries and territories, 1990-2017: a systematic analysis for the global burden of disease study 2017. Lancet 2018;392:1789-858.

7 Appleby J. Nursing workforce crisis in numbers. BMJ 2019;367:1666 4-164.

8 Scheffler RM, Arnold DR. Projecting shortages and surpluses of doctors and nurses in the OECD: what looms ahead. Health Econ Policy Law 2019;14:274-90.

9 World Health Organization a. Health workforce education and training. Available: https://www.who.int/activities/health-workforceeducation-and-training [Accessed 10 Mar 2020].

10 World Health Organization. Global strategy on human resources for health: workforce 2030, 2016. Available: https://www.who.int/ hrh/resources/glob-strat-hrh_workforce2030.pdf [Accessed 24 Mar 2020].

112020 NSI National Health Care. Retention \& RN Staffing Report, 2020: 1.

12 Department of Population and Employment Statistics of the National Bureau of Statistics. China population \& employment statistical yearbook 2020, 2020.

13 Zhou K, Zhang X, Ding Y, et al. Inequality trends of health workforce in different stages of medical system reform (1985-2011) in China. Hum Resour Health 2015;13:94.

14 Yang J-S, Hao D-J. Dilemmas for nurses in China. Lancet 2018;392:30.

15 Ministry of Education of the People's Republic of China. The Ministry of education and the Ministry of health identify vocational colleges to develop nursing specialty areas and define nurses as talent in shortage. China: China MoEotPsRo, 2003.

16 National Health and Family Planning Commission. National nursing development plan (2016-2020. Commission NHaFP, 2016.

17 National Bureau of Statistics of China. Statistical Communique of the People's Republic of China on the 2019 National Economic and Social Development, 2019. Available: https://data.cnki.net/yearbook/ Single/N2020040350

18 World Health Organization. Measuring health workforce inequalities: methods and application to China and India. World Health Organization, 2010.

19 Theodorakis PN, Mantzavinis GD, Rrumbullaku L, et al. Measuring health inequalities in Albania: a focus on the distribution of general practitioners. Hum Resour Health 2006;4:5.

20 Akita T. Decomposing regional income inequality in China and Indonesia using two-stage nested Theil decomposition method. Ann Reg Sci 2003;37:55-77.

21 Gunn V, Muntaner C, $\mathrm{Ng} \mathrm{E}$, et al. The influence of welfare state factors on nursing professionalization and nursing human resources: a time-series cross-sectional analysis, 2000-2015. J Adv Nurs 2019;75:2797-810.

22 World Health Organization b. Health workforce. Available: https:// www.who.int/hrh/nursing midwifery/en/ [Accessed 22 Mar 2020].

23 OECD. Health at a glance 2017: OECD indicators. Paris, 2017.

24 Yun H, Jie S, Anli J. Nursing shortage in China: state, causes, and strategy. Nurs Outlook 2010;58:122-8.

25 The Central People's Government of the People's Republic of China Suggestions Request for medical and health system reform, 2008. Available: http://www.gov.cn/gzdt/2008-10/14/content_1120143. $\mathrm{htm}$

26 Ministry of Education of the People's Republic of China. Notice on Issuing the Catalogue of disciplines for degree Awarding and talent training, 2011. Available: http://www.moe.gov.cn/srcsite/A22/moe 833/201103/t20110308_116439.html [Accessed 08 Mar 2011].

27 China Academic Degree \& Graduate Education Information. Universities list of master of nursing specialist admissions, 2011. Available: https://www.cdgdc.edu.cn/xwyyjsjyxx/gjjl/szfa/hlss/index. shtml

28 Royal College of Nursing. The UK nursing labour market review 2018, 2019.

29 Smiley RA, Lauer P, Bienemy C, et al. The 2017 national nursing workforce survey. J Nurs Regul 2018;9:S1-88. 
30 Zhang $\mathrm{H}$, Tu J. The working experiences of male nurses in China: implications for male nurse recruitment and retention. J Nurs Manag 2020;28:441-9.

31 Yao X, Cheng G, Yang L. Investigation of professional status and occupational cognition among male nurses in China. Chin Nurs Manag 2020;20:1232-5.

32 Hayes LJ, O'Brien-Pallas L, Duffield C, et al. Nurse turnover: a literature review - an update. Int J Nurs Stud 2012;49:887-905.

33 Lavoie-Tremblay M, O'Brien-Pallas L, Gélinas C, et al. Addressing the turnover issue among new nurses from a generational viewpoint. $J$ Nurs Manag 2008;16:724-33.

34 Zheng X. Undergraduate nursing education in Mainland China:overview,opportunities and challenges. Chin J Nurs Edu 2009;6:139-41.

35 Aiken LH, Cimiotti JP, Sloane DM, et al. Effects of nurse staffing and nurse education on patient deaths in hospitals with different nurse work environments. J Nurs Adm 2012;42:S10.

36 Cho E, Sloane DM, Kim E-Y, et al. Effects of nurse staffing, work environments, and education on patient mortality: an observational study. Int J Nurs Stud 2015;52:535-42.
37 Altmann TK. Registered nurses returning to school for a bachelors degree in nursing: issues emerging from a meta-analysis of the research. Contemp Nurse 2011;39:256-72.

38 Rich KL, Nugent KE. A United States perspective on the challenges in nursing education. Nurse Educ Today 2010;30:228-32.

39 Kovner CT, Djukic M, Jun J, et al. Diversity and education of the nursing workforce 2006-2016. Nurs Outlook 2018;66:160-7.

40 Karan A, Negandhi H, Nair R, et al. Size, composition and distribution of human resource for health in India: new estimates using national sample survey and registry data. BMJ Open 2019;9:e025979.

41 Ono T, Schoenstein M, Buchan J. Geographic imbalances in doctor supply and policy responses. In: OECD health working papers, 2014.

42 The Central People's Government of the People's Republic of China. Deepening the medical and health systemt reform, 2009. Available: http://wwwgovcn/jrzg/2009-04/06/content 1278721 htm

43 MacLeod MLP, Stewart NJ, Kulig JC, et al. Nurses who work in rural and remote communities in Canada: a national survey. Hum Resour Health 2017; 15:34-11.

44 Wilson NW, Couper ID, De Vries E, et al. A critical review of interventions to redress the inequitable distribution of healthcare professionals to rural and remote areas. Rural Remote Health 2009;9:1060. 